\title{
PENINGKATAN PEMAHAMAN GURU DALAM MENULIS DAN MEMPUBLIKASIKAN ARTIKEL ILMIAH PADA JURNAL ONLINE
}

\author{
Rino Richardo ${ }^{1}$, Ahmad Anis Abdullah ${ }^{2}$, Tri Rochmadi ${ }^{3}$, \\ Siti Rohayati ${ }^{4}$, Asrifatun Agustini ${ }^{5}$ \\ ${ }^{1}$ Universitas Alma Ata. Email: rinorichardo@almaata.ac.id \\ 2 Universitas Alma Ata. Email: Anis02108882@gmail.com \\ 3 Universitas Alma Ata. Email: trirochmadi@almaata.ac.id \\ 4 Universitas Alma Ata. Email: Rohayati1610@gmail.com \\ 5 Universitas Alma Ata. Email: Asrufatun.a@gmail.com
}

\begin{abstract}
The ability to write scientific articles for teachers is still quite low. While the career development of a teacher, especially in Submitting a Credit Score for promotion, it is very necessary to publish scientific articles as a condition. The writing of this article is part of the implementation of community activities with the aim of increasing teacher understanding in writing and publishing scientific articles carried out in the form of training (workshops). The methods used in this training are lectures, questions and answers, practice to mentoring. The instrument used to measure teachers' understanding abilities related to writing and publication was a pre-test and post-test questionnaire with a Likert scale and was validated. In addition, to measure the level of success of community service activities, an evaluation questionnaire was given to the participants. Based on the results of questionnaire data obtained that the teacher's understanding in writing to submit / publication in online journals increased.
\end{abstract}

Keywords: Writing, Publication, Scientific Articles, Understanding, Teachers

\begin{abstract}
ABSTRAK
Kemampuan dalam menulis artikel ilmiah bagi para guru masih cukup rendah. Sementara pengembangan karir seorang guru terutama dalam Pengajuan Angka Kredit untuk kenaikan golongan sangat diperlukan publikasi artikel ilmiah sebagai salah satu syarat. Tulisan artikel ini merupakan bagian dari pelaksanaan kegiatan masyarakat dengan yang bertujuan untuk meningkatkan pemahaman guru dalam menulis dan mempublikasikan artikel ilmiah yang dilaksanakan dalam bentuk Pelatihan (workshop). Metode yang digunakan dalam pelatihan ini yakni ceramah, tanya jawab, praktek hingga pendampingan. Instrumen yang digunakan untuk mengukur kemampuan pemahaman guru terkait menulis dan publikasi adalah angket pretest dan post-test dengan skala likert dan telah divalidasi. Selain itu, secara umum untuk mengukur tingkat keberhasilan kegaitan diberikan instrumen angket evaluasi kepada para peserta. Berdasarkan hasil isian data angket diperoleh bahwa pemahaman guru dalam menulis hingga mensubmit/publikasi pada jurnal online meningkat.
\end{abstract}

Kata Kunci: Menulis, Publikasi, Artikel Ilmiah, Pemahaman, Guru

\section{PENDAHULUAN}

Upaya pemerintah dalam rangka meningkatkan kualitas guru yang profesional dengan ditandainya pemberian penghargaan berupa sertifikat profesi guru adalah langkah awal dalam menjamin kualitas pendidikan di Indonesia. Melalui proses seleksi yang tidak mudah, seperti penyusunan portofilio, ujian komptensi, hingga pendidikan profesi guru menunjukkan suatu proses bahwa guru yang telah mendapatkan sertifikat 
profesi merupakan guru yang profesional dibidangnya. Tetapi penghargaan tersebut baru merupakan langkah awal, sehingga masih diperlukan Pengembangan Keprofesionalan Berkelanjutan (PKB) seorang guru karena ilmu pengetahuan dan teknologi semakin berkembang seiring dengan perubahan waktu. Jika tidak demikian, maka seorang guru akan jauh tertinggal dari berkembangnya ilmu-ilmu pengetahuan tersebut. Disisi lainnya, pengembangan keprofesionalan sangat bermanfaat bagi peningkatan karir guru tersebut.

Tuntutan PKB ini telah diatur didalam undang-undang guru dan dosen, bahwa guru memiliki kewajiban untuk meningkatkan dan mengembangkan keprofesionalannya. Guru profesional didefinisikan sebagai orang yang memiliki kemampuan dan keahlian khusus dalam bidang keguruan sehingga ia mampu melakukan tugas dan fungsi jabatan guru dengan kemampuan yang maksimal dalam melaksanakan tugasnya (Usman, 2006; Sudrajat, 2013).

Ada beberapa aspek yang dituntut peningkatan profesionalime, salah satunya yaitu peningkatan kemampuan guru/dosen melalui karya ilmiah/hasil penelitian (Marwoto, 2013). Karya ilmiah tersebut salah satunya adalah membuat artikel ilimah. Artikel ilmiah merupakan tulisan yang memuat suatu masalah tertentu berdasarkan hasil kajian dan fakta empiris dengan menggunakan metode ilmiah, dibahas secara mendalam serta disajikan menggunakan bahasa baku dengan format penulisan tertentu (Ghufron, 2014). Agar menjadi sumber informasi yang inspiratif, maka artikel ilmiah tersebut dipublikasi / diterbitkan di Jurnal ilmiah yang telah online.

Jurnal ilmiah adalah sebuah publikasi yang diterbitkan secara berkala oleh organisasi profesi atau institusi akademik yang memuat kumpulan-kumpulan artikel ilmiah dalam bidang keilmuan tertentu (Suryoputro, 2012). Sehingga dapat dikatakan bahwa jurnal ilmiah yang telah online merupakan buku atau kumpulan-kumpulan artikel ilmiah yang diterbitkan secara berkala dan online (dapat diakses melalui internet). Jurnal ilmiah yang dimaksud adalah jurnal ilmiah nasional, minimal jurnal yang telah memiliki ISSN.

Selain merupakan tuntutan keprofesional seorang guru, Aspek kemampuan mempublikasikan artikel ilmiah ini merupakan bagian dari PKB (Richardo, 2016). Banyak guru yang mampu melaksanakan kegiatan penelitian tindakan kelas, namun itu hanya sebatas laporan saja. Makna mampu disini berarti kemampuan untuk memaksimalkan kapasitas individu untuk menyelesaikan tugasnya (Richardo, 2019 ; Cahdriyana, 2019). Sehingga makna mampu disini dimaknai dengan mampu melaksanakan penelitian, dan mampu mempublikasikan hasil penelitian tersebut ke dalam bentuk artikel ilmiah dan terpublikasi pada jurnal online.

Meskipun demikian masih terdapat guru-guru yang masih belum memiliki kemampun dalam menulis artikel ilmiah (Permana, 2017 ; Gunawan, 2018). Kondisi ini juga yang terjadi pada MA Nurul Ummah Yogyakarta, padahal dalam beberapa kesempatan guru-guru telah mendapatkan pelatihan. Tetapi pelatihan yang selama ini diberikan, hanya sebatas teori, tidak intensif dalam hal praktek secara langsung dalam pembuatan artikel. Oleh karena itu, diperlukan adanya pelatihan yang intensif hingga para guru menghasilkan draft artikel yang siap untuk disubmit. Selain itu, tujuan yang terpenting dari pelatihan ini adalah untuk lebih meningkatkan kemampuan guru dalam 
menulis artikel, menguasai struktur artikel, pengelolaan daftar pustaka menggunakan aplikasi mendeley, mencari referensi secara online, hingga mengetahui cara mencari jurnal nasional online dan gaya selingkung jurnal yang menjadi tujuan.

\section{METODE PELAKSANAAN}

Metode yang digunakan pada kegiatan workshop ini meliputi atas ceramah, tanya jawab, praktek hingga pendampingan dalam menulis artikel ilimiah. Materi yang disampaikan terkait dengan struktur artikel, pengelolaan daftar pustaka menggunakan aplikasi mendeley, mencari refernsi secara online, mencari jurnal nasional online dan gaya selingkung jurnal yang menjadi tujuan

\section{Subjek}

Subjek (peserta) kegaitan ini adalah Guru-guru MA Nurul Ummah Yogyakarta yang berjumlah 11 guru. Sedangkan bidang studi dari 11 guru tersebut meliputi matematika, Biologi, komputer, Pendidikan Agama Islam, fisika, Sosiologi, dan Geografi.

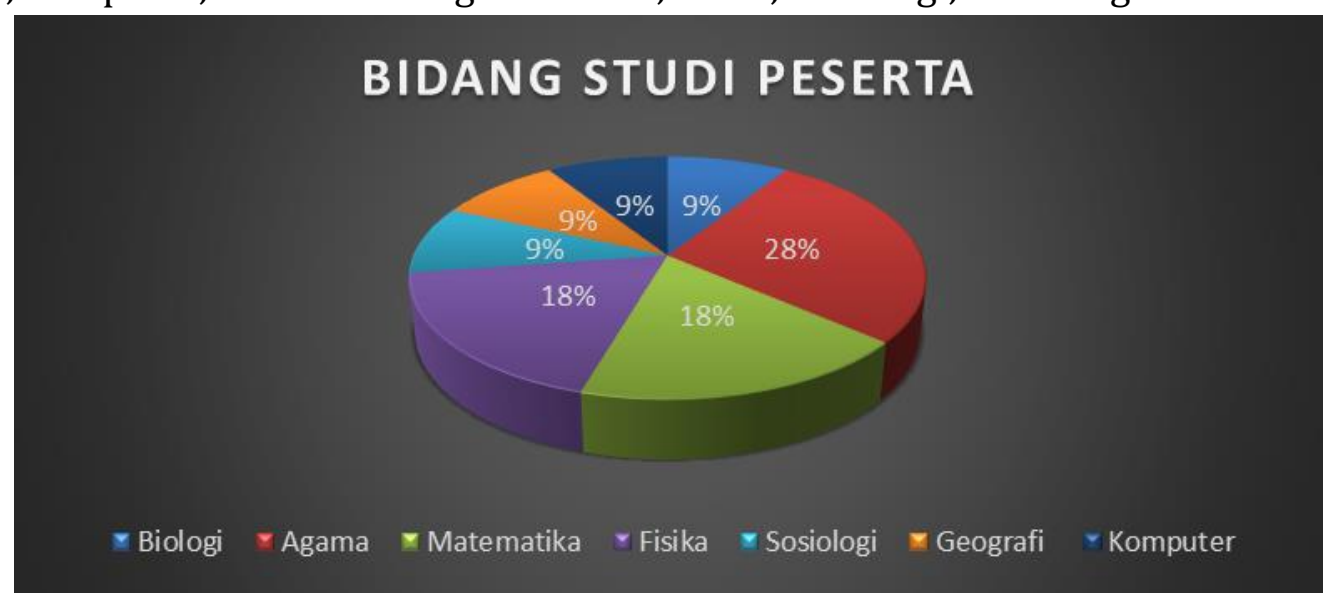

Gambar 1. Deskripsi Bidang Studi Peserta PKM

\section{Instrumen Pengukuran Kemampuan Guru}

Untuk mengetahui bahwa kegiatan ini memberikan dampak yang signifikan terhadap kegiatan yaitu meningkatnya pengetahun guru dalam menulis dan mempublikasikan artikel ilmiah dijurnal nasional online maka para peserta diberikan angket pretes dan posttest untuk mengukur kemampuan peserta dalam memahami materi yang telah disampaikan. Pretest diberikan Sebelum pelaksanaan kegiatan dan memberikan posttes setelah dilakukan kegiatan pelatihan menulis artikel. Adapun daftar isian pertanyaan anget pre-test maupun post-tes yang diberikan adalah sebagai berikut

Tabel 1. Daftar Pertanyaan Angket

\begin{tabular}{ll}
\hline No & \multicolumn{1}{c}{ Pertanyaan Angket } \\
\hline 1 & Bagaimana pemahaman anda terkait urgensi publikasi artikel ilmiah bagi para guru? \\
\hline 2 & Bagaimana pemahaman anda tentang jurnal online dan cara publikasinya? \\
\hline 3 & Bagaimana pemahaman anda dalam mencari referensi artikel di internet? \\
\hline 4 & Bagaimana pemahaman anda terkait gaya selingkung dalam penulisan artikel? \\
\hline 5 & Bagaimana pemahaman anda terkait struktur dari artikel ilmiah? \\
\hline 6 & Bagaimana pemahaman anda terkait isi dari abstrak sebuah artikel? \\
\hline 7 & Bagaimana pemahaman anda terkait teknik menyisipkan gambar di artikel? \\
\hline
\end{tabular}




\begin{tabular}{ll}
\hline 8 & $\begin{array}{l}\text { Bagaimana pemahaman anda terkait teknik mendeskripsikan/menjelaskan gambar/tabel } \\
\text { pada artikel? }\end{array}$ \\
\hline 9 & Bagaimana pemahaman anda terkait penulisan daftar pustaka? \\
\hline 10 & Bagaimana pemahaman anda dengan program aplikasi mendeley? \\
\hline
\end{tabular}

Selain itu peserta juga diberikan angket evaluasi kegiatan PKM. Sebelum dibagikan kepada para peserta, instrumen ini divalidasi terlebih dahulu oleh dosen teman sejawat. Data isian angket kemudian dianalisis secara deskriptif untuk dapat memberikan gambaran terkait peningkatan kemampuan peserta dan hasil pelaksanaan kegiatan secara keseluruhan sebagai bahan evaluasi terhadap kegiatan pengabdian masyarakat yang telah dilakukan. Adapun daftar isian pernyataan angket evaluasi kegiatan PKM sebagai berikut.

Tabel 2. Daftar Pernyataan Angket Evaluasi PKM

\begin{tabular}{cl}
\hline No & \multicolumn{1}{c}{ Pertanyaan } \\
\hline 1 & $\begin{array}{l}\text { Saya merasa puas dengan kegiatan pengabdian masyarakat yang diselenggarakan oleh Tim } \\
\text { Pengabdian Masyarakat (TPM) dari Universitas Alma Ata }\end{array}$ \\
\hline 2 & $\begin{array}{l}\text { Kegiatan pengabdian masyarakat yang diselenggarakan oleh Tim Pengabdian Masyarakat } \\
\text { (TPM) dari Universitas Alma Ata sesuai dengan harapan saya }\end{array}$ \\
\hline 3 & $\begin{array}{l}\text { Personil/anggota yang terlibat dalam kegiatan pengabdian masyarakat memberikan } \\
\text { pelayanan sesuai dengan harapan/tujuan dari kegiatan pelatihan }\end{array}$ \\
\hline 4 & $\begin{array}{l}\text { Setiap keluhan/pertanyaan/permasalahan yang saya ajukan ditindaklanjuti dengan baik } \\
\text { oleh narasumber/anggota yang terlibat }\end{array}$ \\
\hline 5 & $\begin{array}{l}\text { Jika kegiatan ini diselenggarakan kembali atau kegiatan tidak lanjutnya, saya bersedia untuk } \\
\text { berpartisipasi/terlibat }\end{array}$ \\
\hline 6 & $\begin{array}{l}\text { Saya merasa mendapatkan pemahaman yang baik terkait dengan penulisan artikel ilmiah } \\
\text { serta cara mempublikasikannya }\end{array}$ \\
\hline
\end{tabular}

\section{HASIL DAN PEMBAHASAN}

\section{Pra Pelaksanaan PKM}

Pelaksana kegiatan PKM ini terdiri dari 3 Dosen Universitas Alma Ata, yaitu 2 orang dari program studi pendidikan matematika, dan 1 orang dari program studi ilmu sistem informasi serta dibantu oleh 2 orang mahasiswa. Sebelum pelaksanaan PKM, tim pelaksana melaksanakan wawancara kepada wakil kepala sekolah untuk mengetahui kondisi real pemahaman peserta terkait penulisan dan publikasi artikel. Selain itu diadakan kegiatan pre-test untuk mengetahui kemampuan awal dari para peserta. Para peserta diminta untuk mengisi lembar pre-test secara online melalui melalui https://forms.gle/BCpMF7qgFwYSVfkV7 


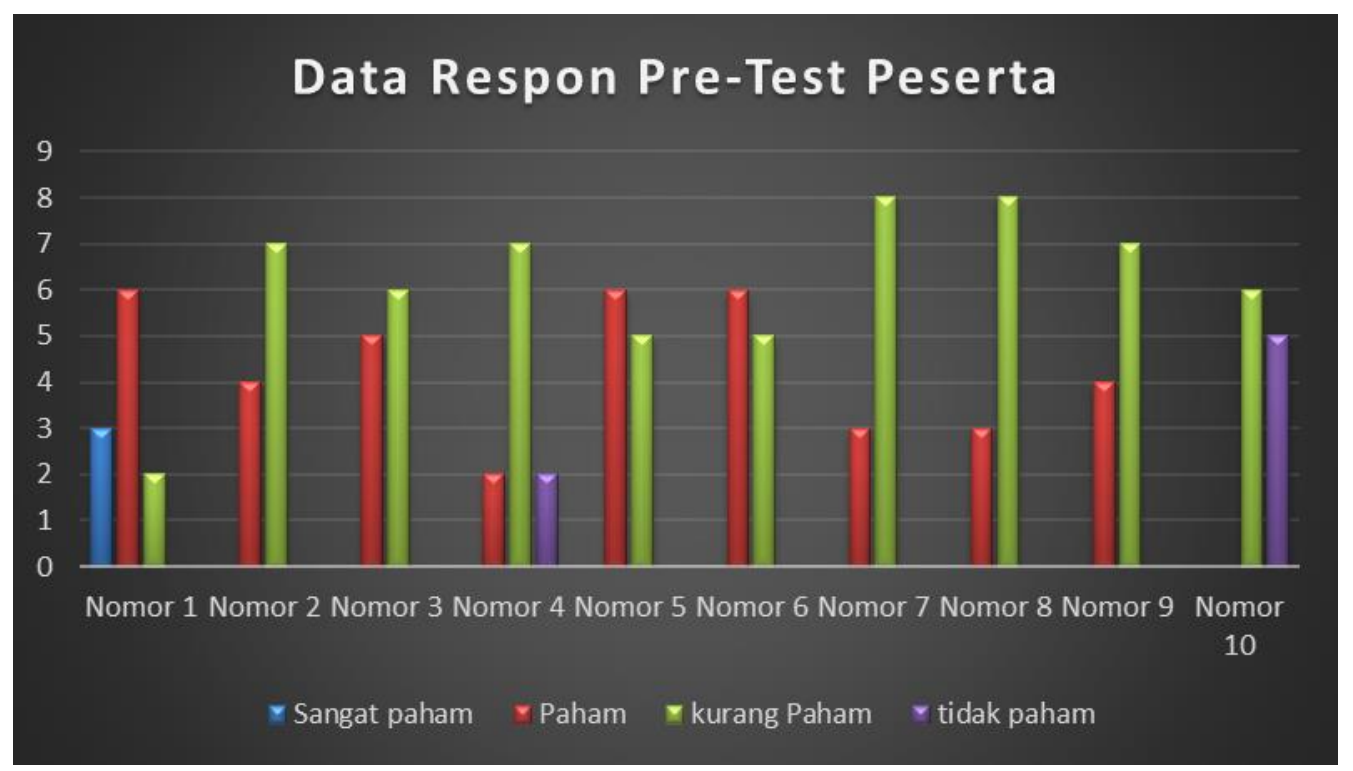

Gambar 2. Grafik Data Respon Pre-Test

Berdasarkan hasil angket pretest, dapat dikatakan bahwa sebagian besar pes erta belum memahami (kurang paham) terhadap pengetahuan terkait penulisan artikel ilmiah, tentang jurnal online, hingga terkait aplikasi mendeley. Hal ini menunjukkan bahwa, pendampingan penulisan artikel ilmiah hingga peserta mampu mensubmit artikel pada jurnal online sangat dibutuhkan.

\section{Pelaksanaan PKM}

Terkait Pelaksanaan, dalam kegiatan ini proses penyampaian materi dan pendampingan sebanyak 18 Sesi, dengan 1 sesinya adalah 60 menit. Adapun rinci pelaksanaannya adalah sebagai berikut

Tabel 2. Kegiatan Pelaksanaan PKM

\begin{tabular}{|c|c|c|c|}
\hline No & Kegiatan & Waktu & Pemateri \\
\hline 1 & $\begin{array}{l}\text { Penyampaian Materi } \\
\text { 1) Konsep Penulisan Artikel Ilmiah } \\
\text { 2) Struktur Ilmiah Bagian } 1\end{array}$ & Sesi 2 - 5 & Rino Richardo, M.Pd \\
\hline 2 & Penyampaian Struktur Ilmiah bagian 2 & Sesi 6-9 & Ahmad Anis Abdullah, M.Sc \\
\hline 3 & $\begin{array}{l}\text { Penyampaian Materi : } \\
\text { 1) Mendeley } \\
\text { 2) Mencari Referensi Online } \\
\text { 3) cara publikasi di OJS }\end{array}$ & Sesi 10-13 & Tri Rochmadi, M.Kom \\
\hline 4 & $\begin{array}{l}\text { Pendampingan Menulis Manuscript dan } \\
\text { Submit Artikel }\end{array}$ & Sesi $14-17$ & $\begin{array}{l}\text { Ahmad Anis, M.Sc } \\
\text { Tri Rochmad, M.Kom } \\
\text { Rino Richardo, M.Pd }\end{array}$ \\
\hline
\end{tabular}

Kegiatan pelatihan dibantu oleh 2 orang mahasiswa dari program studi pendidikan matematika. Selain menjadi asisten instruktur, para mahasiswa juga dapat menjadikan kegiatan ini sebagai bekal agar penelitian akhir yang dibuat dapat berujung pada artikel yang juga siap untuk dipublikasikan pada jurnal-jurnal online nasional. Pada sesi 14 hingga 17, disela sesi tersebut dilakukan review bersama terhadap hasil karya para peserta sehingga para peserta mengetahui hal-hal tertentu yang perlu 
mendapat perhatian khusus. Diharapkan peserta dapat memperbaiki dan menyempurnakan hasil artikelnya.
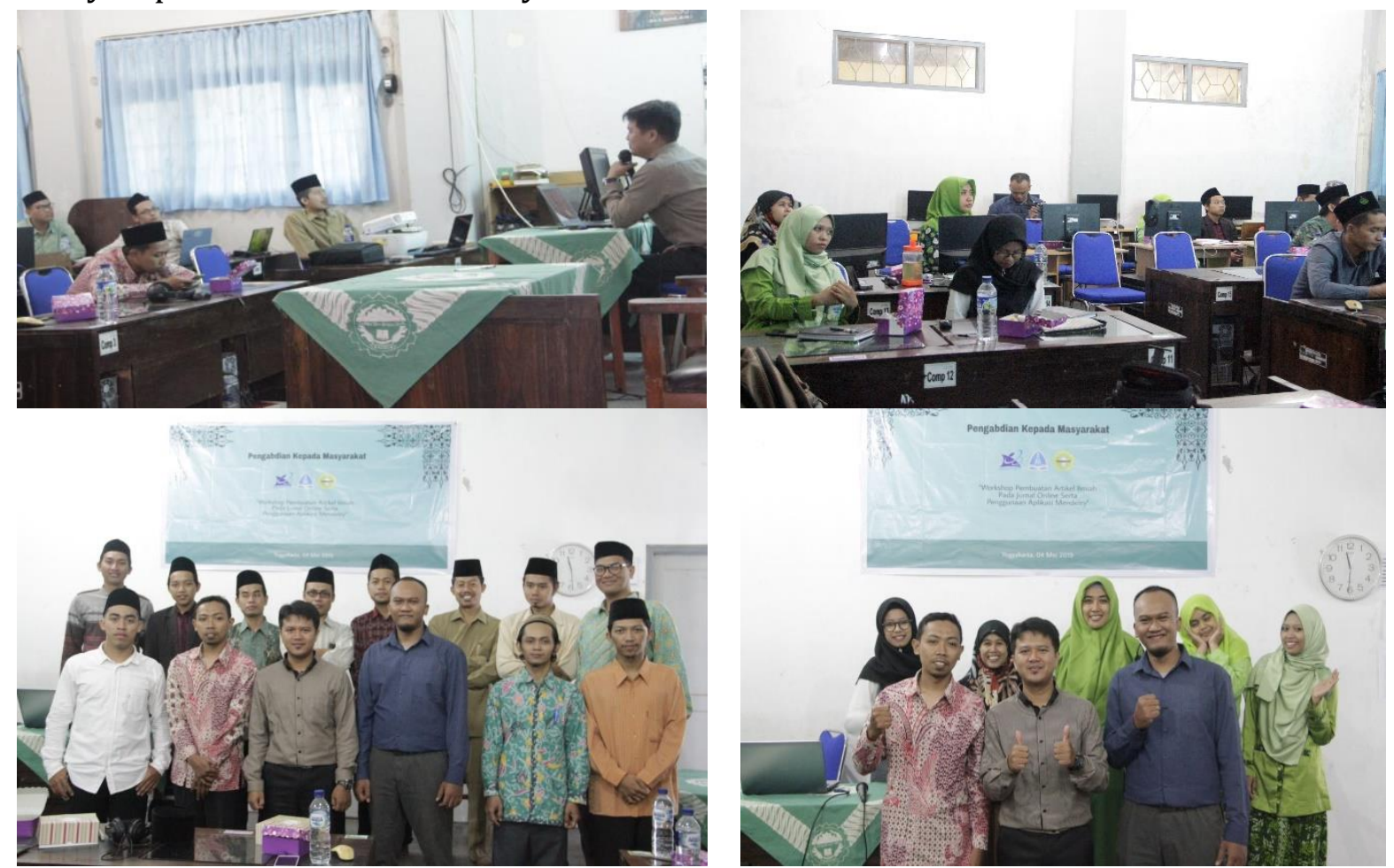

Gambar 3. Gambar Kegiatan PKM

Untuk melihat peningkatan kemampuan para guru dalam menulis artikel ilmiah serta kemampuan mempublikasikan ke jurnal online, maka para peserta diberikan angket post-test diakhir kegiatan. Angket posttest ini diberikan secara online dan dapat diakses melalui https://forms.gle/cbYo3xg6FWmg99Xh9. Berdasarkan hasil pengisian peserta diperoleh data sebagai berikut

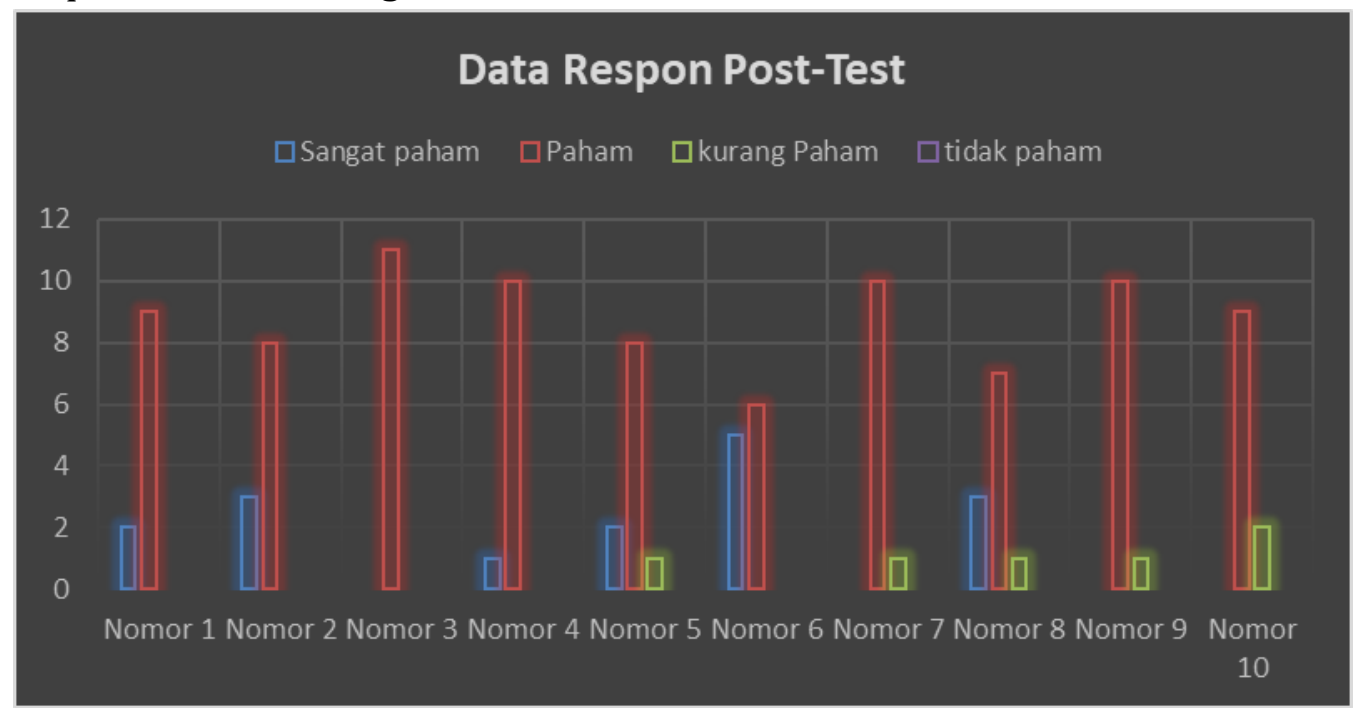

Gambar 4. Data Respon Post-Test 


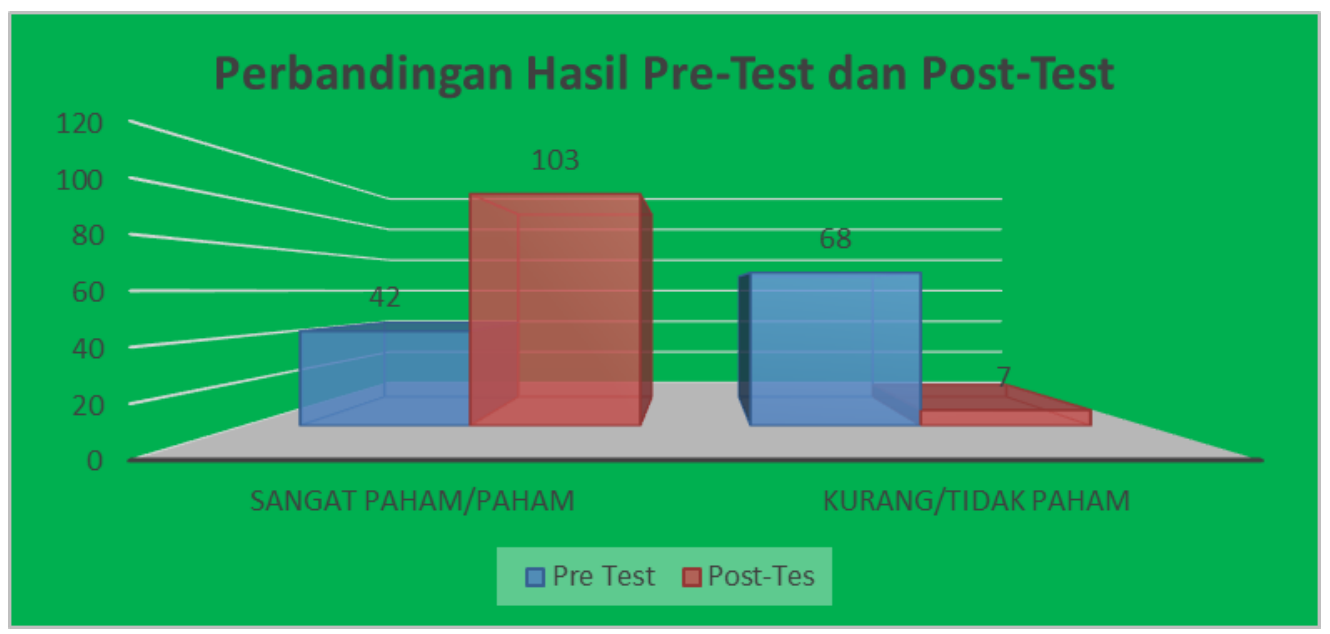

Gambar 5. Perbandingan Hasil Pre dan Post Test

Berdasarkan data Gambar 2 (pre-test) dan Gambar 4 (post-test) terlihat bahwa, indikator "Kurang Paham" dan "Tidak Paham" pada prest-test dari tiap-tiap pertanyaan angket, sudah tidak terdapat pada post-test. Serta berdasarkan hasil perbandingan antara pre test dan post test, tingkat kurang/ketidakpahaman peserta setelah mendapatkan materi workshop mengalami penurunan signifikan. Hal ini menunjukkan bahwa kegiatan PKM yang telah dilakukan telah memberikan efek peningkatan pemahaman kepada peserta terkait penyusunan artikel ilmiah, penggunaaan aplikasi mendeley serta cara mensubmit artikel pada jurnal online.

\section{Pasca Pelaksanaan PKM}

Selanjutnya untuk melihat ketercapaian kegiatan PKM yang telah dilaksanakan berupa Kuesioner Evaluasi Kegiatan Pengabdian Kepada Masyarakat. Kuesioner ini diberikan secara online dan dapat diakses melalui https://forms.gle/eSEdRaUPTF q2bzC77. Berdasarkan hasil pengisian peserta pada angket evaluasi diperoleh data sebagai berikut

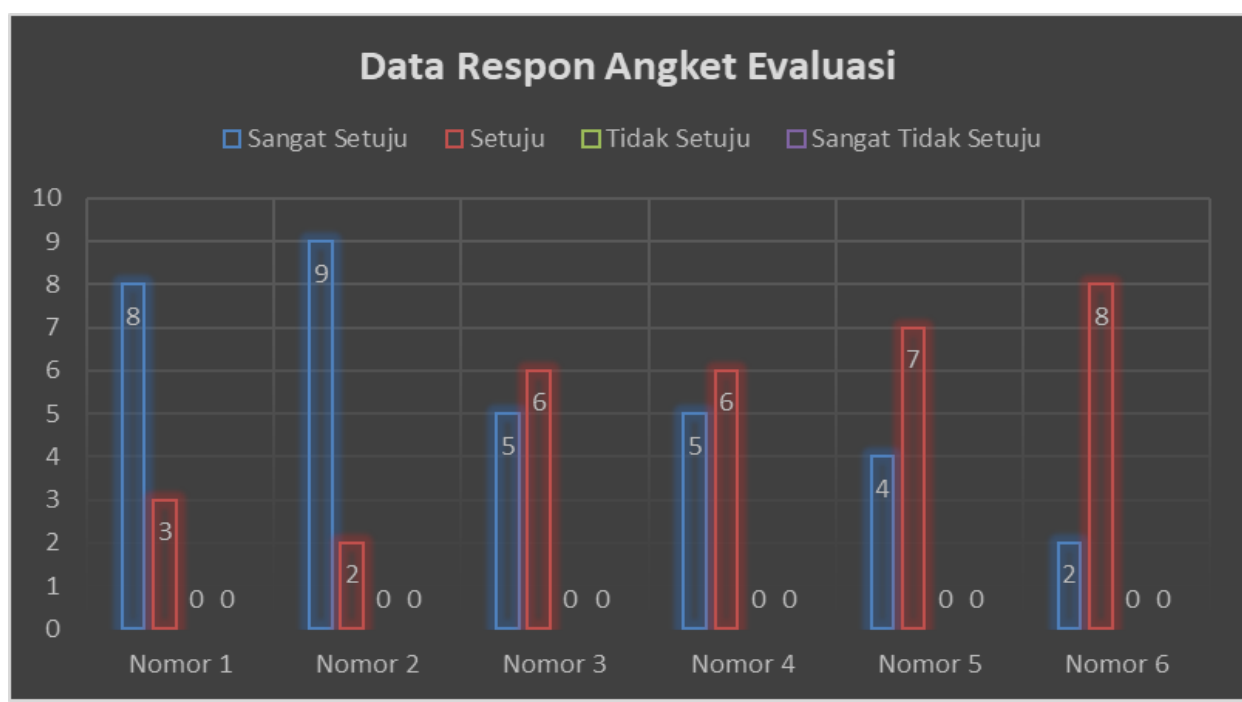

Gambar 6. Data Respon Angket Evaluasi 
Berdasarkan data respon angket evaluasi, dapat dikatakan bahwa sebagian besar peserta merasa puas akan pelayanan, respon yang diberikan oleh Tim PKM dalam mendampingi kegiatan pendampingan peserta dalam membuat hingga mensubmit artikel ilmiah. Tentunya harapan dari kegiatan ini dapat memberikan pengetahuan yang bermanfaat sehingga keberlanjutan dari kegiatan ini dapat diteruskan melalui budaya menulis yang tinggi oleh para peserta.

\section{SIMPULAN}

Berdasarkan hasil dan pembahasan tersebut, maka dapat disimpulkan bahwa kegiatan workshop/pelatihan mampu meningkatkan kemampuan guru dalam menulis artikel ilmiah dan mempublikasikannya serta kegiatan PKM yang telah dilaksanakan telah berjalan dengan baik.

\section{UCAPAN TERIMA KASIH}

Penulis menyampikan terimakasih banyak kepada Direktorat Riset dan Pengabdian Masyarakat Dikti (DRPM) yang telah memberikan dana hibah melalui skema Program Kemitraaan Masyarakat Stimulus (PKMS) tahun 2019, sehingga kegiatan pelatihan/workshop dalam bentuk pengabdian masyarakat dapat terselesaikan dengan baik

\section{DAFTAR RUJUKAN}

Cahdriyana, R. A., Richardo, R., Fahmi, S., \& Setyawan, F. (2019). Pseudo-thinking process in solving logic problem. Journal of Physics: Conference Series, 1188(1), 012090.

Ghufron, S. (2014). Artikel Ilmiah: Anatomi, Bahasa, dan Kesalahannya. EDU-KATA, 1(1), $1-10$.

Gunawan, I., Triwiyanto, T., \& Kusumaningrum, D. E. (2018). Pendampingan Penulisan Artikel Ilmiah bagi Para Guru Sekolah Menengah Pertama. Abdimas Pedagogi: Jurnal Ilmiah Pengabdian kepada Masyarakat, 1(2), 128-135.

Marwoto, P., Sopyan, A., Linuwih, S., Subali, B., \& Ellianawati, E. (2013). Peningkatan Kemampuan Menulis Artikel Ilmiah Sains Guru Sekolah Dasar melalui Kegiatan Pengabdian Masyarakat. Jurnal Abdimas, 17(2), 111-116.

Permana, E. P., Mujiwati, E. S., Sahari, S., Santi, N. N., Damariswara, R., Mukmin, B. A., ... \& Saidah, K. (2017). Pelatihan Penulisan Karya Ilmiah Untuk Guru Sekolah Dasar Pada Anggota Gugus 1 Kecamatan Ringinrejo Kabupaten Kediri. Jurnal ABDINUS: Jurnal Pengabdian Nusantara, 1(1), 53-68.

Richardo, R. (2016). Program Guru Pembelajar: Upaya Peningkatan Profesionalisme Guru di Abad 21. Prosiding Seminar Nasional Matematika dan Pendidikan Matematika.

Richardo, R., \& Martyanti, A. (2019). Developing ethnomathematical tasks in the context of yogyakarta to measure critical thinking ability. Journal of Physics: Conference Series, 1188(1), 012063. 
Sudrajat, A. (2013). Pendekatan Saintifik Ilmiah dalam Proses Pembelajaran. Retrieved from https://akhmadsudrajat.wordpress.com/2013/07/18/pendekatansaintifik ilmiah-dalam-proses-pembelajaran.

Usman, M. U. (2006). Menjadi Guru Profesional. Bandung: PT. Remaja Rosda Karya. 
10 J-Abdipamas, Vol. 3, No. 2 Oktober, 2019 